\title{
Биоиндикационные характеристики структурных и функциональных особенностей растений на примере Malus Mill.
}

\section{Bioindicative characteristics of the structural and functional pecularities of plants on the example of the genus Malus Mill.}

\author{
Пикуленко М. М. ${ }^{1}$, Кумахова Т. Х. ${ }^{2}$ \\ Pikulenko M. M. ${ }^{1}$, Kumachova T. H. ${ }^{2}$ \\ ${ }^{1}$ МГУ имени М. В. Ломоносова, г. Москва, Россия. E-mail:pikulenkomarina@mail.ru \\ ${ }^{2}$ РГАУ-МСХА им. К. А. Тимирязева, г. Москва, Россия. E-mail:tkumachova@yandex.ru \\ ${ }^{1}$ Lomonosov Moscow State University, Moscow, Russia \\ ${ }^{2}$ Russian State Agrarian University - Moscow Timiryazev Agricultural Academy, Moscow, Russia
}

\begin{abstract}
Peферат. С применением современных биофизических и физиологических подходов, а также методов электронной микроскопии изучены особенности фотосинтетического аппарата листьев и созревающих плодов яблони урбанизированных и горных территорий. Полученные биоиндикационные характеристики возможно использовать для оперативного наблюдения урбанофлоры и горных агроландшафтов.
\end{abstract}

Ключевые слова. Адаптация, биоиндикация, митохондрии, хлоропласты, Malus Mill.

Summary. Using modern biophysical and physiological approaches, as well as electron microscopy methods, the features of the photosynthetic apparatus of leaves and ripening apple fruits in urbanized and mountainous areas have been studied. The obtained bioindication characteristics can be used for operational observation of urban flora and mountain agrolandscapes.

Key words. Adaptation, bioindication, chloroplasts, mitochondria, Malus Mill.

Динамический контроль состояния древесных растений урбанизированных и природных территорий, в том числе и горных, в связи с необходимостью систематической коррекции ландшафтов (агроландшафтов) и планирования агротехнических мероприятий в последние годы представляет интерес для исследователей (Венедиктов и др., 2000; Ninemets et al., 2002; Ташекова, Торопов, 2017). Известно, что основные структурные и функциональные характеристики растений, как и всех других живых организмов, определяются особенностями организации клеток, внутриклеточных компартментов, а также структур энергобеспечения (особенно хлоропластов и митохондрий). Отсутствие исчерпывающих материалов о взаимодействиях внутриклеточных компартментов плодов древесных растений при различных стрессовых ситуациях на урбанизированных территориях и в горных условиях, характеризующихся высокой интенсивностью солнечной радиации, богатой УФ-лучами, резкими колебаниями температуры в течение суток, не дает полного представления о структурных и физиологических адаптациях растений в целом. При действии внешних факторов среды изменяются их продукционные характеристики, начинающиеся с реакций фотосинтетического аппарата (ФСА) (Кумахова и др., 2008). Следует отметить, что на работу ФСА растений оказывают влияние не только факторы, вызывающие непосредственное влияние на какую-либо стадию фотосинтеза, но и условия, нарушающие другие метаболические пути растений. Источником информации об эффективности первичных процессов фотосинтеза может служить флуоресценция хлорофилла (Фл хл), изменение которой при разных воздействиях можно регистрировать в режиме реального времени без повреждения тканей растения. В совокупности со структурными особенностями эти сведения могут быть весьма полезными при отборе наиболее приспособленных к резким изменениям климатических условий форм культурных растений и в качестве биоиндикационных характеристик. 
Целью данной работы было изучение структурных и функциональных особенностей клеток околоплодника яблони, выращенных в горных агроландшафтах и на урбанизированных территориях, а также выявление цитологических и физиологических биоиндикационных характеристик.

Материал для исследования собран на Северном Кавказе в степной (300 м над ур. м.) и горной зонах (1200 м) и на территории МГУ имени М. В. Ломоносова. Объектом исследования были разные представители рода Malus Mill. Образцы отбирали из средней части кроны трех модельных деревьев. Подготовку материала для электронно-микроскопических исследований проводили по модифицированной нами методике (Кумахова, Меликян, 1989). Материал фиксировали глутаровым альдегидом (на $0,1 \mathrm{M}$ фосфатном буфере с $\mathrm{pH}=7,2)$ и $1 \%$-м раствором четырехокиси осмия. Затем образцы обезвоживали в серии спиртов и ацетонов возрастающей концентрации и заливали в Эпон-812. Ультратонкие срезы изготовляли на ультрамикротоме LKB-III-8801A. Срезы контрастировали 2 \%-м водным раствором уранил-ацетата $\left(37^{\circ} \mathrm{C}\right)$ и цитратом свинца по Рейнольдсу.

Флуоресценцию хлорофилла измеряли на микроучастках слоя хлоропластов (диаметр участка 100 мкм) с помощью флуориметра с модулированным освещением Microscopy PAM и программы WinControl (Walz). Тонкий срез поверхности плодов яблони длиной около 10 мм и шириной до 7 мм в водном растворе в прозрачной камере устанавливали на столике инвертированного микроскопа Ахіоvert-25 CFL (Carl Zeiss, Германия), оснащенного флуориметрической насадкой Microscopy PAM (Walz, Германия). При оценке функционального состояния ФСА растений использовали сопоставление интенсивностей Фл хл при возбуждении вспышками света разной интенсивности. Показано, что соотношение квантовых выходов Фл хл при различных интенсивностях возбуждающего света соответствует эффективности первичных процессов фотосинтеза (Van Kooten, Snel, 1990; Shreiber et al, 1995). Измеренная таким образом эффективность первичных процессов фотосинтеза представляет собой безразмерную энергетическую характеристику фотосинтеза, аналогичную коэффициенту полезного действия. Благодаря низкой интенсивности измерительный свет не оказывал влияния на состояние ФСА, что проявлялось по высокому отношению переменной Фл к максимальной Фл $\left(\Delta F / F_{m}\right)$. Действующий свет направляли от верхнего осветителя микроскопа Axiovert-25 CFL. Свет проходил через синий светофильтр С 3 С-22, пропускающий лучи с длиной волны до 580 нм. Интенсивность фотосинтетически активной радиации (ФАР) на уровне клетки определяли с помощью 818-UV радиометра (Newport, CA, США) и рассчитывали плотность потока квантов. Максимальная интенсивность света составляла 100 мкмоль квантов/( $\left.{ }^{2} \mathrm{c}\right)$. Ослабление интенсивности света достигалось с помощью стеклянных нейтральных светофильтров. Эффективный квантовый выход фотопереноса электронов в ФС II $\left(\Delta F / F_{m}\right)$ рассчитывали по уравнениям $\Delta F / F_{m}{ }^{\prime}=\left(F_{m}{ }^{\prime}-F\right) / F_{m}{ }^{\prime}$, где $F_{m}$ и $F_{m}{ }^{\prime}$ обозначают максимальные выходы Фл, индуцируемые насыщающим световым импульсом после темновой адаптации и на действующем свету, соответственно, а $F$ обозначает текущий уровень Фл на действующем свету (Van Kooten, Snel, 1990; Shreiber et al, 1995). Величина $\Delta F / F_{m}{ }^{\prime}$ при постоянной интенсивности освещения пропорциональна скорости нециклического потока электронов и служит показателем ФСА. В опытах по измерению параметров индукции Фл ФСА использовали листья и созревающие зеленые плоды яблони, произрастающей на равнине, размером от 2 до $4 \mathrm{~cm}$, срезанные утром в день исследований при температуре воздуха около $18^{\circ} \mathrm{C}$. Измерения проводили с помощью флуориметра PEA (Plant Efficiency Analyzer, Hansatech, Англия) на срезах наружных слоев плодов толщиной 2-4 мм, площадью около 1,5 см². Образцы листьев и плодов адаптировали к темноте в течение 5 мин, а затем освещали красным светом (максимум при 650 нм, интенсивность- 1500 мкмоль / $\left(\mathrm{M}^{2} \mathrm{c}\right)$, длительность освещения $\left.-2 \mathrm{c}\right)$.

По данным трансмиссионной электронной микроскопии (ТЭМ) популяция хлоропластов представлена, главным образом, в субэпидермальном слое, состоящем из трех слоев толстостенных колленхимоподобных клеток. Их главная особенность - пристеночное положение и хорошо развитая мембранная система. Кроме того, для хлоропластов околоплодника характерны многочисленные картины слияния и деления, а также контакты между собой и с другими органеллами. У молодых плодов в гранальной структуре стромы хлоропластов видны более рыхлые области, содержащие птДНК (в 1 хлоропласте по 3-4 нуклеоида). В структурном плане отмечается накопление в строме хлоропластов различных включений (крахмальные зерна, пластоглобулы, белковые включения, фитоферритин-железосодержащий белок). В некоторых хлоропластах тилакоиды упакованы довольно плотно, в их внутренних пространствах локализованы электронноплотные вещества, свидетельствующие об их вероятном уча- 
стии в синтетических процессах. По нашим наблюдениям более развитая система контактов пластид отмечается в клетках плодов, выращенных на больших высотах (1200 м над ур. м.), их количество в два раза больше, по сравнению с равнинными (300 м). При этом с увеличением высоты произрастания плодовых растений кардинально перестраивается мембранная система хлоропластов, в них граны состоят из меньшего числа тилакоидов. По нашему мнению, выявленные структурные особенности фотосинтетического аппарата (ФСА) можно использовать как биоиндикационный параметр среды.

Результаты исследований свидетельствуют, что ФСА хлорофилла плодов, выросших в горных и равнинных условиях при исследовании без действующего освещения, характеризуются одинаковой высокой потенциальной эффективностью нециклического транспорта электронов. При освещении светом 50 мкмоль квантов / ( ${ }^{2}$ с) эффективность фотосинтеза хлорофилла плодов, выросших в горах, существенно ниже наблюдаемых на равнинных плодах. Сравнение параметров Фл на одном том же препарате при воздействии света и без освещения показало, что на равнинных плодах изменение режима освещения не приводит к значительным изменениям в скорости нециклического потока электронов, а на препаратах горных плодов уменьшается на 50 \%. На наш взгляд, зарегистрированные различия показателей ФСА, по-видимому, связаны с более ранним завершением онтогенеза в горах.

Полученные в экспериментах индукционные кривые флуоресценции (Фл) листьев яблони включали три фазы нарастания. Основное отличие индукционных кривых Фл плодов на ранней стадии онтогенеза состояло в том, что наблюдался переход $\mathrm{O}-\mathrm{K}-\mathrm{J}$, который отсутствовал в листьях. По данным литературы, пик К обычно проявляется после тепловой обработки $\left(40{ }^{\circ} \mathrm{C}\right)$ листьев и сопряжен с понижением квантовой эффективности ФС 2, что объясняют нарушением кислород- выделяющего комплекса и дисбалансом притока - оттока электронов на уровне ФС 2. В наших опытах без тепловой обработки пик К достигался при 400 мс от момента включения света; его появление не сопровождалось снижением квантового выхода переноса электронов в ФС 2. Полученные значения параметра Fv / Fm в плодах яблони составили 0,71-0,86; т. е. были аналогичны показателям фотосинтетической активности листьев. Это позволяет использовать данный параметр как биоиндикационную характеристику при оценке физиологического состояния плодов.

Таким образом, полученные нами материалы показывают, что изучение фотосинтетического аппарата листьев и плодов яблони Malus Mill. (Rosaceae) с применением биофизических и физиологических подходов, а также методов электронной микроскопии, позволяет выявить разнообразные биоиндикационные параметры адаптации растений к изменяющимся условиям внешней среды. Эти данные будут полезны и для прикладных целей, в частности при коррекции и планировании ландшафтов (агроландшафтов) урбанизированных и природных территорий.

\section{ЛИТЕРАТУРА}

Венедиктов П. С., Казимироко Ю. В., Кренделева Т. Е., Кукарских Г. П., Макарова В.В., Погосян С. И., Яковлева О. В., Рубин А. Б. Изучение физиологического состояния древесных растений по характеристикам флуоресцеции в коре однолетних побегов деревьев // Экология, 2000. - № 5. - С. 338-342.

Кумахова Т. Х., Булычев А. А., Крупенина Н. А., Пикуленко М. М. Активность фотосинтеического аппарата как маркер структурно-функциональных изменений клеток растений при адаптации к горным условиям на примере плодов яблони // Доклады ТСХА, 2008. - Вып. 280. - С. 122-126.

Кумахова Т. Х., Меликян А. П. Ультраструктура кутикулы плодов сортов Malus domestica (Rosaceae) // Ботанический журнал, 1989. - Т. 74., № 3. - С. $328-332$.

Ташекова A. Ж., Торопов A. C. Использование листье растений как биогеохимических индикаторов состояния городской среды // Изв. Томск. политех. универ., 2017. - Т. 328, № 5. - С. 114-124.

Ninemets $U$., Portsmuth A., Truus L. Leaf structure and photosynthetic characteristics and biomass allocation to foliage in relation to foliar nitrogen content and tree size in tree Betula species // Ann. Bot., 2002. - Vol. 89, №2. P. 191-204.

Schreiber $\boldsymbol{U}$., Bilger W., Neubauer $\boldsymbol{C}$. Chlorophyll Fluorescence as a Nonintrusive Indicator for Rapid Assessment of in Vivo Photosynthesis // Ecophysiology of Photosynthesis / Eds Schulze E.-D., Caldwell M.M. Berlin: Springer, 1995. - P. $49-70$.

Van Kooten O., Snel J. F. H. The Use of Chlorophyll Fluorescence Nomenclature in Plant Stress Physiology // Photosynth. Res., 1990. - V. 25. - P. 147-150. 